\title{
Use of Sodium-Glucose Co-Transporter-2-Inhibitors (SGLT2-Is) and Risk of Lower Limb Amputation
}

Citation for published version (APA):

Werkman, N. C. C., Nielen, J. T. H., van den Bergh, J. P. W., Ejskjaer, N., Røikjer, J., Schaper, N. C., Rossi, B., Klungel, O., Vestergaard, P., de Vries, F., \& Driessen, J. H. M. (2021). Use of Sodium-Glucose Co-Transporter-2-Inhibitors (SGLT2-Is) and Risk of Lower Limb Amputation. Current Drug Safety, 16(1), 62-72. https://doi.org/10.2174/1574886315666200805103053

Document status and date:

Published: 01/01/2021

DOI:

10.2174/1574886315666200805103053

Document Version:

Publisher's PDF, also known as Version of record

Document license:

Taverne

Please check the document version of this publication:

- A submitted manuscript is the version of the article upon submission and before peer-review. There can be important differences between the submitted version and the official published version of record.

People interested in the research are advised to contact the author for the final version of the publication, or visit the DOI to the publisher's website.

- The final author version and the galley proof are versions of the publication after peer review.

- The final published version features the final layout of the paper including the volume, issue and page numbers.

Link to publication

\footnotetext{
General rights rights.

- You may freely distribute the URL identifying the publication in the public portal. please follow below link for the End User Agreement:

www.umlib.nl/taverne-license

Take down policy

If you believe that this document breaches copyright please contact us at:

repository@maastrichtuniversity.nl

providing details and we will investigate your claim.
}

Copyright and moral rights for the publications made accessible in the public portal are retained by the authors and/or other copyright owners and it is a condition of accessing publications that users recognise and abide by the legal requirements associated with these

- Users may download and print one copy of any publication from the public portal for the purpose of private study or research.

- You may not further distribute the material or use it for any profit-making activity or commercial gain

If the publication is distributed under the terms of Article $25 \mathrm{fa}$ of the Dutch Copyright Act, indicated by the "Taverne" license above, 


\title{
RESEARCH ARTICLE
}

\section{Use of Sodium-Glucose Co-Transporter-2-Inhibitors (SGLT2-Is) and Risk of Lower Limb Amputation}

\author{
Nikki C.C. Werkman ${ }^{1,2,3}$, Johannes T.H. Nielen ${ }^{3}$, Joop P.W. van den Bergh ${ }^{4,5,6,7}$, Niels Ejskjaer ${ }^{8,9,10}$, \\ Johan Røikjer $^{8,9,10}$, Nicolaas C. Schaper ${ }^{1,11}$, Bernardette Rossi ${ }^{12}$, Olaf Klungel ${ }^{2}$, Peter Vestergaard ${ }^{8,9}$, \\ ${ }^{11}$, Frank de Vries ${ }^{*}, 1,2,3$ and Johanna H.M. Driessen ${ }^{1,2,3,4}$
}

\begin{abstract}
${ }^{I}$ Cardiovascular Research Institute Maastricht (CARIM), Maastricht University, Maastricht, The Netherlands; ${ }^{2}$ Division of Pharmacoepidemiology and Clinical Pharmacology, Utrecht Institute of Pharmaceutical Sciences, Utrecht, The Netherlands; ${ }^{3}$ Department of Clinical Pharmacy and Toxicology, Maastricht University Medical Center +, Maastricht, The Netherlands; ${ }^{4}$ School for Nutrition and Translational Research in Metabolism (NUTRIM), Maastricht University, Maastricht, The Netherlands; ${ }^{5}$ Department of Internal Medicine, Division of Rheumatology, Maastricht University Medical Center+, Maastricht, The Netherlands; ${ }^{6}$ Department of Internal Medicine, VieCuri Medical Center, Venlo, The Netherlands; ${ }^{7}$ Faculty of Medicine and Life Sciences, Hasselt University, Hasselt, Belgium; ${ }^{8}$ Department of Clinical Medicine, Aalborg University, Aalborg, Denmark; ${ }^{9}$ Steno Diabetes Center North Denmark, Aalborg University Hospital, Aalborg, Denmark; ${ }^{10}$ Department of Endocrinology, Aalborg University Hospital, Aalborg, Denmark; ${ }^{11}$ Department of Internal Medicine, Division of Endocrinology, Maastricht University Medical Center+, Maastricht, The Netherlands; ${ }^{I 2}$ Directorate Pharmaceutical Affairs, Department for Policy in Health, Ministry for Health, Malta
\end{abstract}

\begin{abstract}
Background: Treatment with sodium-glucose co-transporter-2-inhibitors (SGLT2-Is), such as canagliflozin, has been associated with an increased risk of lower limb amputations (LLAs) in type 2 diabetes mellitus (T2DM). However, conflicting results have been reported for different SGLT2-Is and the underlying mechanism is unclear.

Objective: To investigate the risk of LLA and diabetic foot ulcer with SGLT2-I use compared to other anti-diabetic drugs and to explore hypovolemia as a potential underlying mechanism.

Methods: A cohort study was conducted using data from the Clinical Practice Research Datalink GOLD (2013-2019). The study population $(\mathrm{N}=51,847)$ consisted of T2DM patients over 18 years of age with at least one prescription of a non-insulin anti-diabetic drug. Concomitant diuretic use and the presence of signs of hypovolemia were determined to assess the potential underlying mechanism. Cox proportional hazard models were used to estimate the hazard ratio (HR) for LLA in current SGLT2-I use versus current sulphonylurea (SU) use. Analyses were adjusted for lifestyle variables, comorbidities, and concomitant drug use.
\end{abstract}

ART I CLE H IS T O R Y

Received: April 02, 2020 Revised: June 03, 2020 Accepted: June 16, 2020

DOI:

$10.2174 / 1574886315666200805103053$
Results: Current SGLT2-I use was not associated with an increased risk of LLA compared to current SU use (fully adjusted HR $0.70 ; 95 \%$ confidence interval $0.38-1.29$ ). Concomitant use of diuretics and the presence of signs of hypovolemia were not associated with an increased risk of LLA.

Conclusion: Use of SGLT2-Is, with or without signs of hypovolemia, was not associated with an increased risk of LLA or DFU versus current SU use. Future studies powered to detect potential differences between individual SGLT2-Is are required to rule out a canagliflozin-specific effect.

Keywords: SGLT2 inhibitors, Type 2 diabetes mellitus, Amputation, Hypovolemia, Cohort study, CPRD.

\section{INTRODUCTION}

Lower limb amputation (LLA) is a highly feared complication of type 2 diabetes mellitus (T2DM) and is approximately ten times more common among individuals with

*Address correspondence to this author at the Cardiovascular Research Institute Maastricht (CARIM), Maastricht University, Maastricht, The Netherlands; Division of Pharmacoepidemiology and Clinical Pharmacology, Utrecht Institute of Pharmaceutical Sciences, Utrecht, The Netherlands and Department of Clinical Pharmacy and Toxicology, Maastricht University Medical Center+, Maastricht, The Netherlands;

E-mail: f.devries@uu.nl diabetes compared to those without diabetes [1]. Most of these amputations are preceded by a diabetic foot ulcer, and particularly patients with such an ulcer and peripheral arterial disease are at risk of amputation [2]. Sodium-glucose cotransporter-2-inhibitors (SGLT2-Is) are innovative drugs used in the treatment of T2DM. These drugs prevent the reabsorption of plasma glucose in the proximal renal tubule and therefore lower the plasma glucose concentration [3]. SGLT2-Is are associated with positive cardiac and renal outcomes in various meta-analyses of randomized controlled trials (RCTs) [4-6]. However, the results of the Canagliflozin Cardiovascular Assessment Study (CANVAS) Pro- 
gram indicated that individuals using SGLT2-I canagliflozin had increased risk of LLA versus placebo, especially at the level of the toe or metatarsal [7].

After the first publication of increased risk of LLA in patients using SGLT2-Is, subsequent studies reported conflicting results. Some observational cohort studies found a higher risk of LLA associated with SGLT2-I use [8-10] whereas other cohort studies did not [11,12]. A meta-analysis of RCTs as well as a meta-analysis of observational studies did not observe an increase in LLAs associated with SGLT2-I use $[6,13]$. These contrasting findings might be attributable to differences in study population and study design, especially the use of different reference groups such as metformin or glucagon-like peptide 1 receptor agonist users. Alternatively, the studied SGLT2-I may affect study results, as there might be a substance-specific effect (i.e., related to canagliflozin) rather than a class effect [14].

In addition, the underlying mechanism that would be responsible for the increased risk of LLA is still debated. Hypovolemia with reduced tissue perfusion, due to the increased osmotic diuresis caused by SGLT2-I use, could be one of the important pathways leading to amputation [15]. In line with this hypothesis, an increased risk of LLA has previously been observed among individuals with T2DM using diuretics [16]. If hypovolemia would play a role in the underlying aetiology, we would expect an increased risk of LLA specifically in SGLT2-I users with hypovolemia, or with concomitant use of diuretics or drugs that target the renin-angiotensin system. However, the role of hypovolemia has not been addressed specifically in previous studies.

Therefore, the aim of the current study was to investigate the risk of LLA and diabetic foot ulcer in the general diabetic population with SGLT2-I use compared to other antidiabetic drugs. In addition, the possibility of SGLT2-I induced hypovolemia as an underlying mechanism was explored by using signs of hypovolemia and concomitant antihypertensive drug use.

\section{METHODS}

Data were obtained from the Clinical Practice Research Datalink (CPRD) GOLD. The CPRD GOLD contains computerized medical records of 674 primary care practices in the United Kingdom, representing $6.9 \%$ of the national population in 2013. The data recorded in the CPRD include demographic information, prescription details, clinical events, preventive care provided, specialist referrals, hospital admissions, and major outcomes since 1987 [17]. The independent scientific advisory committee of the CPRD approved the study protocol (number 19_199R). No further ethical approval was required [18].

We conducted a retrospective cohort study. A base cohort was created by including all individuals aged 18 years or older and starting with metformin only between January 1998 and October 2019. In order to ensure that individuals had not previously used metformin or other anti-diabetic drugs, at least one year of valid data collection was required. From the base cohort, individuals with a first-ever prescription for a sulphonylurea (SU), dipeptidyl peptidase 4 inhibitor (DPP4-I) or SGLT2-I between 01-01-2013 and 31-10-
2019 were selected. This study period was chosen as SGLT2-Is have been available as of 01-01-2013 in the United Kingdom. The index date (i.e., start of follow-up) was determined by the date of the first prescription for an SU, DPP4-I or SGLT2-I.

\subsection{Exposure}

The total duration of follow-up was divided into intervals of 30 days. The exposure to non-insulin anti-diabetic drugs (NIADs) was determined at the start of each interval. Based on the time since the most recent prescription, intervals were classified as current (1-90 days) or past ( $>90$ days) NIAD use. Individuals could move between current and past use intervals. Current use intervals were further stratified by the following mutually exclusive categories of NIAD use: current use of either an SU, DPP4-I, or SGLT2-I, current combined use (combinations of an SU and/or DPP4-I, and/or SGLT2-I) and current use of other NIADs (No SU, DPP4-I or SGLT2-I). Our exposure of interest was current SGLT2-I use and current SU use was the reference group.

Besides, current SGLT2-I use was further stratified by cumulative dose and continuous duration of use. The cumulative dose was calculated at each current SGLT2-I interval by reviewing the total amount of previously prescribed SGLT2-I in defined daily doses (DDDs). Cumulative dose categories were expressed in canagliflozin equivalents, using the WHO ATC/DDD index [19]. Continuous duration of use was defined as the time from the first prescription until the start of an interval, allowing a gap of 60 days between the estimated end date of a prescription and the start of the next prescription. The estimated end date of a prescription was determined by using the prescribed quantity and the written dosage instruction. Moreover, current SGLT2-I use was stratified by the substance (canagliflozin, dapagliflozin or empagliflozin) in order to study substance-specific effects.

In order to determine if hypovolemia in SGLT2-I users was associated with an increased risk of LLA, current SGLT2-I use was stratified by concomitant use of antihypertensive drugs in the previous 3 months and signs of hypovolemia as reported in the primary care database in the previous year. Antihypertensive drugs included loop diuretics, thiazide diuretics, potassium-sparing diuretics, betablockers, angiotensin-converting enzyme (ACE) inhibitors or angiotensin II receptor blockers (ARBs). Signs of hypovolemia included a record of dehydration, (orthostatic) hypotension, oliguria, or a serum urea/creatinine ratio higher than 0.1 .

\subsection{Outcomes}

Individuals were followed from their index date to either the end of data collection, the individual's death or the outcome of interest, whichever came first. The primary outcome of interest was the risk of LLA, defined as any lower limb amputation. For secondary analyses, we were interested in distal LLAs. We distinguished the following amputation levels: (1) one or more toes, (2) through and below one or more metatarsal bones, (3) through and below the ankle. The secondary outcomes of interest were LLA by level, development of diabetic foot ulcer (unspecified) and development of an ischaemic diabetic foot ulcer. 


\subsection{Potential Confounders}

Potential risk factors for the outcomes of interest were identified and were assessed by reviewing the computerized medical records. Sex, smoking status, alcohol use, and body mass index (BMI) were determined on the index date. All other potential risk factors were determined in a timedependent manner (i.e., at the start of each interval). The following confounders were considered: age, duration of T2DM, the most recently recorded blood glucose level and $\mathrm{HbA1c}$ measurement within the previous 12 months, a history of retinopathy or neuropathy; diabetic foot ulcer or nontraumatic LLA prior to inclusion in the study; a history of foot infection, cellulitis of lower limb, osteomyelitis, ulcer of the lower extremity, renal impairment, atrial fibrillation, coronary arteriosclerosis, coronary revascularisation, acute coronary syndrome, heart failure, ischaemic heart disease, peripheral arterial disease, peripheral vascular disease, cerebrovascular disease and stroke, hyperlipidaemia and skin ulcer; and the use of the following drugs in the previous 6 months: insulin, loop diuretics, thiazide diuretics, potassium sparing diuretics, beta-blockers, calcium-channel blockers, digoxin, organic nitrates, platelet inhibitors, anticoagulants, lipid-lowering drugs, ACE-inhibitors and ARBs. All variables were treated as categorical variables (with the exception of age) and dummy indicator variables were used to account for missing data.

\subsection{Statistical Analyses}

Cox proportional hazard models were used to estimate the hazard ratio (HR) for the outcomes of interest comparing current SGLT2-I use to current SU use. Current SGLT2-I use was stratified by age, sex, cumulative dose, continuous duration of use and SGLT2-I substance. In order to test hypovolemia as the potential mechanism for an increased risk of LLA, current SGLT2-I use was further stratified by antihypertensive drug use in the three months before an interval and by the presence of signs of hypovolemia in the year prior to an interval. Wald tests were used to statistically compare the results of these stratifications. Multivariable analyses were used to address potential confounding in the Cox proportional hazard models. The HRs were adjusted for age, sex, and the confounders mentioned in the previous section if they showed a $>5 \%$ change in the beta-coefficient for current SGLT2-I use in an age/sex-adjusted analysis, or if clinical evidence from literature suggested their inclusion as a confounder. As a sensitivity analysis, current DPP4-I use was used as the reference group instead of current SU use. In a second sensitivity analysis, the gap used to determine the continuous duration of use was changed from 60 days to 30 days. Finally, we excluded individuals with previous LLAs. Data was analyzed using SAS version 9.4 (SAS Institute, Cary, NC, USA).

\section{RESULTS}

Fig. (1) shows the processing of the original data extraction, to the base cohort and subsequent study cohort. Table 1 shows the baseline characteristics of the SGLT2-I users, SU users and DPP4-I users. A total of 51,847 NIAD users were included, of whom 10,927 were SGLT2-I users. The median follow-up time was 3.0 years (interquartile range [IQR] 1.54.4) for SGLT2-I users and 4.4 years (IQR 2.4-5.7) for SU users. The median duration of T2DM was higher in SGLT2-I users (5.9 years [IQR 2.4-9.3]) than in SU users (2.1 years [IQR 0.3-5.0]). The percentage of women was $42.6 \%$ in SGLT2-I users and $42.8 \%$ in SU users. SGLT2-I users were younger on average (57.8 years) than SU users (61.6 years). Metabolic control was suboptimal with a mean HbAlc of $8.8 \%$ (SGLT2-I users) and 8.7\% (SU users). The number of patients with cardiovascular events and heart failure was relatively low in both cohorts.

Table 1. Baseline characteristics of SGLT2-I users, DPP4-I users, and SU users ${ }^{\mathrm{a}, \mathrm{b}}$.

\begin{tabular}{|c|c|c|c|c|c|c|}
\hline \multirow{2}{*}{$\begin{array}{l}\text { Characteristic } \\
\text { Median follow-up time, (years (IQR)) }\end{array}$} & \multicolumn{2}{|c|}{$\begin{array}{l}\text { SGLT2-I users } \\
\qquad(\mathrm{N}=\mathbf{1 0 , 9 2 7 )}\end{array}$} & \multicolumn{2}{|c|}{$\begin{array}{c}\text { SU users } \\
(N=19,651)\end{array}$} & \multicolumn{2}{|c|}{$\begin{array}{l}\text { DPP4-I users } \\
(N=\mathbf{2 0 , 9 7 9 )}\end{array}$} \\
\hline & 3.0 & $(1.5-4.4)$ & 4.4 & $(2.4-5.7)$ & 3.9 & $(2.1-5.4)$ \\
\hline Median duration of T2DM (years (IQR)) & 5.9 & $(2.4-9.3)$ & 2.1 & $(0.3-5.0)$ & 4.4 & $(1.8-7.8)$ \\
\hline Number of women & 4,659 & $(42.6)$ & 8,419 & $(42.8)$ & 8,748 & $(41.7)$ \\
\hline Mean age at index date (years (SD)) & 57.8 & $(10.5)$ & 61.6 & $(13.2)$ & 63.9 & $(12.5)$ \\
\hline $18-49$ years & 6,056 & $(55.4)$ & 8,528 & $(43.4)$ & 7,648 & $(36.5)$ \\
\hline $50-59$ years & 3,418 & $(31.3)$ & 5,438 & $(27.7)$ & 6,098 & $(29.1)$ \\
\hline $60-69$ years & 1,324 & $(12.1)$ & 3,948 & $(20.1)$ & 4,923 & $(23.5)$ \\
\hline
\end{tabular}




\begin{tabular}{|c|c|c|c|c|c|c|}
\hline \multirow{2}{*}{$\begin{array}{l}\text { Characteristic } \\
\text { BMI }\end{array}$} & \multicolumn{2}{|c|}{$\begin{array}{l}\text { SGLT2-I users } \\
\qquad(\mathrm{N}=\mathbf{1 0 , 9 2 7 )}\end{array}$} & \multicolumn{2}{|c|}{$\begin{array}{c}\text { SU users } \\
(\mathrm{N}=\mathbf{1 9 , 6 5 1 )}\end{array}$} & \multicolumn{2}{|c|}{$\begin{array}{l}\text { DPP4-I users } \\
(N=\mathbf{2 0 , 9 7 9 )}\end{array}$} \\
\hline & & & & & & \\
\hline Mean BMI at index date $\left(\mathrm{kg} / \mathrm{m}^{2}(\mathrm{SD})\right)$ & 35.5 & $(6.9)$ & 32.0 & $(6.8)$ & 32.6 & $(6.6)$ \\
\hline$<20.0 \mathrm{~kg} / \mathrm{m}^{2}$ & 5 & $(0.0)$ & 59 & $(0.3)$ & 42 & $(0.2)$ \\
\hline $20.0-24.9 \mathrm{~kg} / \mathrm{m}^{2}$ & 296 & $(2.7)$ & 2,268 & $(11.5)$ & 1,706 & $(8.1)$ \\
\hline $25.0-29.9 \mathrm{~kg} / \mathrm{m}^{2}$ & 1,943 & $(17.8)$ & 5,954 & $(30.3)$ & 6,088 & $(29.0)$ \\
\hline $30.0-34.9 \mathrm{~kg} / \mathrm{m}^{2}$ & 3,543 & $(32.4)$ & 5,865 & $(29.8)$ & 6,603 & $(31.5)$ \\
\hline$\geq 35 \mathrm{~kg} / \mathrm{m}^{2}$ & 5,104 & $(46.7)$ & 5,325 & $(27.1)$ & 6,441 & $(30.7)$ \\
\hline Missing & 36 & $(0.3)$ & 180 & $(0.9)$ & 99 & $(0.5)$ \\
\hline \multicolumn{7}{|l|}{ Smoking status } \\
\hline Never & 3,127 & $(28.6)$ & 5,531 & $(28.1)$ & 5,768 & $(27.5)$ \\
\hline Current & 1,755 & $(16.1)$ & 3,562 & $(18.1)$ & 3,230 & $(15.4)$ \\
\hline Ex & 6,039 & $(55.3)$ & 10,537 & $(53.6)$ & 11,972 & $(57.1)$ \\
\hline Missing & 6 & $(0.1)$ & 21 & $(0.1)$ & 9 & $(0.0)$ \\
\hline \multicolumn{7}{|l|}{ Alcohol use } \\
\hline No & 3,130 & $(28.6)$ & 6,137 & $(31.2)$ & 6,645 & $(31.7)$ \\
\hline Yes & 7,592 & $(69.5)$ & 13,064 & $(66.5)$ & 13,998 & $(66.7)$ \\
\hline Missing & 205 & $(1.9)$ & 450 & $(2.3)$ & 336 & $(1.6)$ \\
\hline \multicolumn{7}{|l|}{$\mathrm{HbA} 1 c^{c}$} \\
\hline Mean HbA1c (\% (SD)) & 8.8 & $(1.6)$ & 8.7 & $(1.8)$ & 8.4 & $(1.5)$ \\
\hline$<6.0 \%$ & 88 & $(0.8)$ & 245 & $(1.2)$ & 232 & $(1.1)$ \\
\hline $6.0-6.9 \%$ & 1,073 & $(9.8)$ & 2,431 & (12.4) & 3,023 & (14.4) \\
\hline $7.0-7.9 \%$ & 2,590 & $(23.7)$ & 4,874 & $(24.8)$ & 6,442 & $(30.7)$ \\
\hline $8.0-8.9 \%$ & 2,523 & $(23.1)$ & 3,768 & $(19.2)$ & 4,769 & $(22.7)$ \\
\hline$\geq 9.0 \%$ & 4,247 & $(38.9)$ & 6,345 & $(32.3)$ & 5,747 & $(27.4)$ \\
\hline Missing & 406 & $(3.7)$ & 1,988 & $(10.1)$ & 766 & $(3.7)$ \\
\hline \multicolumn{7}{|l|}{ Blood glucose ${ }^{c}$} \\
\hline Mean blood glucose (mmol/L (SD)) & 12.0 & $(4.6)$ & 12.8 & $(5.9)$ & 11.4 & $(4.6)$ \\
\hline$<6.0 \mathrm{mmol} / \mathrm{L}$ & 184 & $(1.7)$ & 412 & $(2.1)$ & 446 & $(2.1)$ \\
\hline $6.0-7.4 \mathrm{mmol} / \mathrm{L}$ & 444 & $(4.1)$ & 1,108 & $(5.6)$ & 1,173 & $(5.6)$ \\
\hline $7.5-9.0 \mathrm{mmol} / \mathrm{L}$ & 662 & $(6.1)$ & 1,508 & $(7.7)$ & 1,739 & $(8.3)$ \\
\hline$\geq 9.0 \mathrm{mmol} / \mathrm{L}$ & 3,143 & $(28.8)$ & 6,852 & (34.9) & 6,125 & $(29.2)$ \\
\hline Missing & 6,494 & $(59.4)$ & 9,771 & $(49.7)$ & 11,496 & $(54.8)$ \\
\hline \multicolumn{7}{|l|}{ History of Comorbidities } \\
\hline Retinopathy & 2,753 & $(25.2)$ & 3,272 & (16.7) & 4,992 & $(23.8)$ \\
\hline Neuropathy & 659 & $(6.0)$ & 846 & $(4.3)$ & 1,170 & $(5.6)$ \\
\hline Diabetic foot ulcer & 166 & $(1.5)$ & 204 & $(1.0)$ & 322 & $(1.5)$ \\
\hline
\end{tabular}




\begin{tabular}{|c|c|c|c|c|c|c|}
\hline \multirow{2}{*}{$\begin{array}{l}\text { Characteristic } \\
\text { Non-traumatic lower limb amputation }\end{array}$} & \multicolumn{2}{|c|}{$\begin{array}{c}\text { SGLT2-I users } \\
(\mathbf{N}=\mathbf{1 0 , 9 2 7 )}\end{array}$} & \multicolumn{2}{|c|}{$\begin{array}{c}\text { SU users } \\
(\mathrm{N}=\mathbf{1 9 , 6 5 1 )}\end{array}$} & \multicolumn{2}{|c|}{$\begin{array}{l}\text { DPP4-I users } \\
(N=\mathbf{2 0 , 9 7 9 )}\end{array}$} \\
\hline & 55 & $(0.5)$ & 117 & $(0.6)$ & 111 & $(0.5)$ \\
\hline Foot infection & 361 & $(3.3)$ & 464 & $(2.4)$ & 624 & $(3.0)$ \\
\hline Cellulitis of lower limb & 318 & $(2.9)$ & 595 & $(3.0)$ & 672 & $(3.2)$ \\
\hline Ulcer of lower extremity & 169 & $(1.5)$ & 339 & $(1.7)$ & 442 & $(2.1)$ \\
\hline Skin ulcer & 274 & $(2.5)$ & 458 & $(2.3)$ & 617 & $(2.9)$ \\
\hline Renal impairment & 522 & $(4.8)$ & 2,353 & $(12.0)$ & 3,588 & $(17.1)$ \\
\hline Cerebrovascular disease and stroke & 490 & $(4.5)$ & 1.398 & $(7.1)$ & 1.656 & $(7.9)$ \\
\hline Coronary revascularisation & 215 & $(2.0)$ & 534 & $(2.7)$ & 668 & $(3.2)$ \\
\hline Acute coronary syndrome & 82 & $(0.8)$ & 182 & $(0.9)$ & 210 & $(1.0)$ \\
\hline Heart failure & 232 & $(2.1)$ & 769 & $(3.9)$ & 975 & $(4.6)$ \\
\hline Ischaemic heart disease & 1,271 & $(11.6)$ & 2,905 & $(14.8)$ & 3,398 & $(16.2)$ \\
\hline Peripheral arterial disease & 159 & $(1.5)$ & 382 & $(1.9)$ & 481 & $(2.3)$ \\
\hline Peripheral vascular disease & 157 & $(1.4)$ & 400 & $(2.0)$ & 452 & $(2.2)$ \\
\hline Hyperlipidaemia & 2,183 & $(20.0)$ & 3,809 & $(19.4)$ & 4,545 & $(21.7)$ \\
\hline \multicolumn{7}{|l|}{ Drugs used within 6 months before } \\
\hline Insulin & 1,494 & $(13.7)$ & 277 & $(1.4)$ & 700 & $(3.3)$ \\
\hline Loop diuretics & 655 & $(6.0)$ & 2,079 & $(10.6)$ & 2,518 & $(12.0)$ \\
\hline Thiazide diuretics & 1,714 & $(15.7)$ & 3,051 & $(15.5)$ & 3,540 & $(16.9)$ \\
\hline Potassium sparing diuretics & 250 & $(2.3)$ & 665 & $(3.4)$ & 783 & $(3.7)$ \\
\hline Beta-blockers & 2,018 & $(18.5)$ & 4,315 & $(22.0)$ & 4,989 & $(23.8)$ \\
\hline Calcium-channel blockers & 3,007 & $(27.5)$ & 5,031 & $(25.6)$ & 6,217 & $(29.6)$ \\
\hline ACE-inhibitors & 4,913 & $(45.0)$ & 7,487 & $(38.1)$ & 9,265 & $(44.2)$ \\
\hline Angiotensin II receptor blockers & 1,844 & $(16.9)$ & 2,759 & $(14.0)$ & 3,545 & $(16.9)$ \\
\hline Digoxin & 122 & $(1.1)$ & 599 & $(3.0)$ & 622 & $(3.0)$ \\
\hline Organic nitrates & 564 & $(5.2)$ & 1,367 & $(7.0)$ & 1,543 & $(7.4)$ \\
\hline Platelet inhibitors & 2,734 & $(25.0)$ & 5,283 & $(26.9)$ & 6,456 & $(30.8)$ \\
\hline Anticoagulants & 301 & $(2.8)$ & 1,081 & $(5.5)$ & 1,304 & $(6.2)$ \\
\hline Lipid-lowering drugs & 8,236 & $(75.4)$ & 13,359 & $(68.0)$ & 16,168 & $(77.1)$ \\
\hline
\end{tabular}

Abbreviations: SGLT2-I: sodium-glucose co-transporter-2 inhibitor; DPP4-I: dipeptidyl peptidase-4 inhibitor; SU: sulphonylurea; IQR: inter quartile range; SD: standard deviation; BMI: body mass index; HbA1c: glycosylated haemoglobin type A1c; ACE: angiotensin converting enzyme.

${ }^{a}$ Data are presented as number (\%) of individuals, unless stated otherwise.

${ }^{\mathrm{b}}$ Combined users $(\mathrm{N}=290)$ are not shown.

${ }^{\mathrm{c}}$ Most recently recorded value in the past 12 months. 


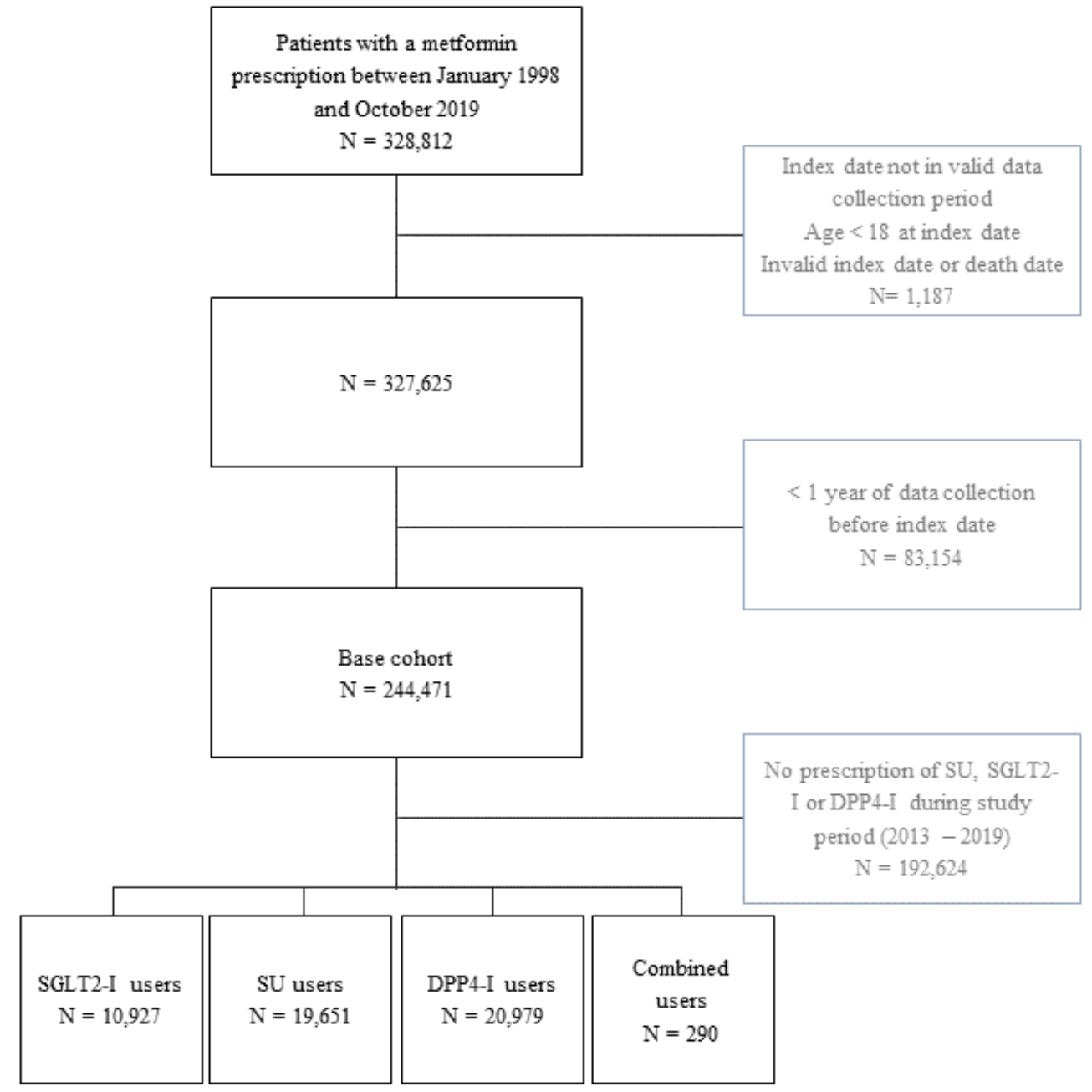

Fig. (1). Flow chart showing the selection from the original data extraction to the base cohort and the final study cohort. Combined users had a prescription of a combination of SGLT2-I and/or SU and/or DPP4-I at index date.

We observed 16 LLAs with current SGLT2-I use and 50 LLAs with current SU use, and the corresponding incidence rates (IRs) were 0.97 and 1.29 per 1000 person years (PY), respectively. The risk of LLA was similar with current SGLT2-I use compared to current SU use (Table 2), with a fully adjusted HR of 0.70 (95\% confidence interval [CI] 0.38-1.29). There was no increased risk for a specific level of LLA with current SGLT2-I use compared to current SU use. We observed 55 cases of diabetic foot ulcer in current SGLT2-I use, yielding a fully adjusted HR of $0.81(95 \%$ CI $0.58-1.14$ ) compared to SU use (data not shown). There were no reported events of ischaemic diabetic foot ulcer with current SGLT2-I use.

Compared to SU use, the risk of LLA in SGLT2-I use did not increase with higher cumulative dose exposure or longer continuous duration of use (Table 3 ). The fully adjusted HR for the highest cumulative dose group $(>145.8 \mathrm{~g}$ canagliflozin equivalents) was 0.96 (95\% CI $0.33-2.77)$ and the fully adjusted HR for the longest continuous duration of use category ( $\geq 2.0$ years) was 1.11 (95\% CI $0.42-2.93$ ).

Of all SGLT2-I prescriptions during follow-up, 13\% were for canagliflozin, $62 \%$ for dapagliflozin, and $25 \%$ for empagliflozin. The IRs of LLAs were 2.3/1000 PY for canagliflozin, $0.83 / 1000 \mathrm{PY}$ for dapagliflozin, and 0.65/1000 PY for empagliflozin. Due to the small number of events, we did not run statistical tests on these stratifications.

Current SGLT2-I use was stratified by concomitant use of several antihypertensives and by signs of hypovolemia (Table 4). There was no increased risk of LLA in current SGLT2-I use in case of concomitant use of loop diuretics, thiazide diuretics, potassium-sparing diuretics, beta-blockers, ACE-inhibitors or ARBs. In addition, a serum urea/creatinine ratio $>0.1$ was not associated with an increased risk of LLA. The other signs of hypovolemia are not shown, as there were no SGLT2-I users with an LLA and record of dehydration, (orthostatic) hypotension or oliguria. The Wald tests did not yield significant results, confirming that there was no difference between the results of these stratifications.

In the first sensitivity analysis, in which DPP4-I use was used as the reference group instead of SU use, the results were not materially altered. The fully adjusted HR for LLA in current SGLT2-I use compared to current DDP4-I use was 0.88 (95\% CI $0.48-1.61)$. In the second sensitivity analysis, 
Table 2. Risk of LLA in past and current NIAD use compared to current SU use, for current SGLT2-I use stratified by sex, age, and site of LLA.

\begin{tabular}{|c|c|c|c|c|c|c|}
\hline \multirow[b]{2}{*}{ Past NIAD use } & \multirow{2}{*}{$\begin{array}{r}\begin{array}{r}\text { Number of } \\
\text { LLAs }\end{array} \\
(\mathbf{N}=\mathbf{1 9 3}) \\
20\end{array}$} & \multirow{2}{*}{$\begin{array}{r}\text { IR (/1000 } \\
\text { PY) } \\
0.35\end{array}$} & \multicolumn{2}{|c|}{$\begin{array}{c}\text { Age/sex adjusted HR } \\
(95 \% \text { CI })\end{array}$} & \multicolumn{2}{|c|}{$\begin{array}{l}\text { Fully adjusted HR } \\
(95 \% \mathrm{CI})\end{array}$} \\
\hline & & & 0.31 & $(0.18-0.52)$ & 0.32 & $(0.19-0.55)^{f}$ \\
\hline Current SU use & 50 & 1.29 & \multicolumn{2}{|c|}{ Reference } & \multicolumn{2}{|c|}{ Reference } \\
\hline Current DPP4 - I use & 38 & 1.18 & 0.93 & $(0.61-1.42)$ & 0.80 & $(0.52-1.24)^{f}$ \\
\hline Current SGLT2-I use & 16 & 0.97 & 0.86 & $(0.48-1.53)$ & 0.70 & $(0.38-1.29)^{f}$ \\
\hline \multicolumn{7}{|l|}{ By sex ${ }^{b}$} \\
\hline Males & 10 & 1.07 & 0.67 & $(0.33-1.36)$ & 0.49 & $(0.23-1.02)^{\mathrm{g}}$ \\
\hline Females $^{c}$ & 6 & 0.84 & 1.64 & $(0.56-4.78)$ & & \\
\hline $50-59$ years & 5 & 0.84 & 1.10 & $(0.35-3.46)$ & & \\
\hline $60-69$ years & 7 & 1.35 & 0.93 & $(0.38-2.29)$ & & \\
\hline $70+$ years & $<5$ & 0.98 & 0.69 & $(0.16-3.01)$ & & \\
\hline \multicolumn{7}{|l|}{ By site of LLA ${ }^{e}$} \\
\hline One or more toes & 8 & 0.49 & 1.11 & $(0.47-2.63)$ & 0.67 & $(0.28-1.63)^{h}$ \\
\hline $\begin{array}{l}\text { Through/below one or } \\
\text { more metatarsal bones }\end{array}$ & 8 & 0.49 & 1.13 & $(0.48-2.65)$ & 0.71 & $(0.29-1.71)^{h}$ \\
\hline Through/below ankle & 9 & 0.55 & 1.16 & $(0.51-2.62)$ & 0.66 & $(0.28-1.55)^{\mathrm{i}}$ \\
\hline
\end{tabular}

Abbreviations: LLA: lower limb amputation; IR: incidence rate; PY: person years; HR: hazard ratio; CI: confidence interval; NIAD: non-insulin anti-diabetic drug; SU: sulphonylurea; DPP4-I: dipeptidyl peptidase-4 inhibitor; SGLT2-I: sodium-glucose cotransporter-2 inhibitor

${ }^{a}$ Combined use of at least two of the following NIADs: an SU and/or DPP4-I and/or SGLT2-I.

${ }^{\mathrm{b}}$ Compared with controls of the same sex.

${ }^{\mathrm{c}}$ No fully adjusted HR possible due to the limited number of LLAs.

${ }^{\mathrm{d}}$ Compared with controls in the same age category.

"Stratification is built up per site. "One or more toes" only includes LLAs of the toes, "Through/below one or more metatarsal bones" includes all LLAs up to this level (i.e. LLAs of one or more toes and through/below one or more metatarsal bones) and "Through/below ankle" includes all LLAs up to this level (i.e. LLA of the toes, metatarsal bones and through/below the ankle).

${ }^{\mathrm{f}}$ Adjusted for sex, age, smoking status, T2DM duration, the use of insulin in the 6 months before, a history of retinopathy, neuropathy, foot infection, peripheral vascular disease, skin ulcer and previous diabetic foot ulcer or LLA.

${ }^{\mathrm{g}}$ Adjusted for age, diabetes duration, the use of insulin in the 6 months before, a history of skin ulcer, neuropathy, foot infection and previous diabetic foot ulcer or LLA.

${ }^{\mathrm{h}}$ Adjusted for sex, age, diabetes duration and the use of insulin in the 6 months before.

iAdjusted for sex, age, diabetes duration, the use of insulin in the 6 months before and previous diabetic foot ulcer.

The number of included confounders in each Cox regression model that estimated adjusted HRs was based on a maximum of one confounder per ten events [30].

Table 3. Risk of LLA in past and current NIAD use compared to current SU use, for current SGLT2-I use stratified by cumulative dose exposure and continuous duration of use.

\begin{tabular}{|l|r|r|r|r|r|r|}
\hline & $\begin{array}{r}\text { Number of } \\
\text { LLAs } \\
\text { (N= 193) }\end{array}$ & $\begin{array}{r}\text { IR (/1000 } \\
\text { PY) }\end{array}$ & \multicolumn{3}{|c|}{$\begin{array}{r}\text { Age/sex adjusted HR } \\
(95 \% \text { CI) }\end{array}$} & $\begin{array}{r}\text { Fully adjusted HR } \\
(95 \% \text { CI) }\end{array}$ \\
\hline Past NIAD use & 20 & 0.35 & 0.31 & $(0.18-0.52)$ & 0.32 & $(0.19-0.55)$ \\
\hline Current SU use & 50 & 1.29 & \multicolumn{2}{|c|}{ Reference } & \multicolumn{2}{|c|}{ Reference } \\
\hline Current DPP4-I use & 38 & 1.18 & 0.93 & $(0.61-1.42)$ & 0.80 & $(0.52-1.24)$ \\
\hline Current combined use ${ }^{\text {b }}$ & 54 & 1.45 & 1.16 & $(0.79-1.71)$ & 1.05 & $(0.70-1.57)$ \\
\hline Current other NIAD use & 15 & 0.99 & 0.85 & $(0.48-1.53)$ & 0.76 & $(0.41-1.39)$ \\
\hline Current SGLT2-I use & 16 & 0.97 & 0.86 & $(0.48-1.53)$ & 0.70 & $(0.38-1.29)$ \\
\hline
\end{tabular}




\begin{tabular}{|c|c|c|c|c|c|c|}
\hline By cumulative dose & & & & & & \\
\hline$\leq 73.0 \mathrm{~g}$ canagliflozin equivalents & 7 & 0.76 & 0.66 & $(0.30-1.48)$ & 0.55 & $(0.24-1.23)$ \\
\hline $73.1-145.8 \mathrm{~g}$ canagliflozin equivalents & 5 & 1.29 & 1.14 & $(0.45-2.90)$ & 0.91 & $(0.35-2.38)$ \\
\hline$>145.8$ g canagliflozin equivalents & $<5$ & 1.17 & 1.07 & $(0.38-3.02)$ & 0.96 & $(0.33-2.77)$ \\
\hline \multicolumn{7}{|l|}{ By continuous duration of use } \\
\hline No continuous duration of use & 0 & $\mathrm{~N} / \mathrm{A}$ & $\mathrm{N} / \mathrm{A}$ & & N/A & \\
\hline$<1.0$ years & 6 & 0.66 & 0.62 & $(0.27-1.47)$ & 0.52 & $(0.22-1.25)$ \\
\hline $1.0-1.9$ years & 5 & 1.26 & 1.12 & $(0.44-2.84)$ & 0.91 & $(0.35-2.36)$ \\
\hline$\geq 2.0$ years & 5 & 1.46 & 1.35 & $(0.53-3.44)$ & 1.11 & $(0.42-2.93)$ \\
\hline
\end{tabular}

Abbreviations: LLA: lower limb amputation; IR: incidence rate; PY: person years; HR: hazard ratio; CI: confidence interval; NIAD: non-insulin anti-diabetic drug; SU: sulphonylurea; DPP4-I: dipeptidyl peptidase-4 inhibitor; SGLT2-I: sodium-glucose cotransporter-2 inhibitor; N/A: not applicable.

${ }^{a}$ Adjusted for sex, age, smoking status, diabetes duration, the use of insulin in the 6 months before, a history of retinopathy, neuropathy, foot infection, peripheral vascular disease, skin ulcer and previous diabetic foot ulcer or LLA.

${ }^{\mathrm{b}}$ Combined use of at least two of the following NIADs: an SU and/or DPP4-I and/or SGLT2-I.

The number of included confounders in each Cox regression model that estimated adjusted HRs was based on a maximum of one confounder per ten events [30].

Table 4. Risk of LLA in past and current NIAD use compared to current SU use, for current SGLT2-I use stratified by concomitant antihypertensive use and signs of hypovolemia.

\begin{tabular}{|c|c|c|c|c|c|c|}
\hline & $\begin{array}{r}\text { Number of } \\
\text { LLAs } \\
(\mathrm{N}=193)\end{array}$ & $\begin{array}{r}\text { IR }(/ \mathbf{1 0 0 0} \\
\text { PY) }\end{array}$ & \multicolumn{2}{|c|}{$\begin{array}{l}\text { Age/sex adjusted HR } \\
\qquad(95 \% \mathrm{CI})\end{array}$} & \multicolumn{2}{|c|}{$\begin{array}{l}\text { Multivariate adjusted } \mathrm{HR}^{\mathrm{a}} \\
(\mathbf{9 5 \%} \mathrm{CI})\end{array}$} \\
\hline Past NIAD use & 20 & 0.35 & 0.31 & $(0.18-0.52)$ & 0.32 & $(0.19-0.55)$ \\
\hline Current SU use & 50 & 1.29 & \multicolumn{2}{|r|}{ Reference } & \multicolumn{2}{|r|}{ Reference } \\
\hline Current DPP4 - I use & 38 & 1.18 & 0.93 & $(0.61-1.42)$ & 0.80 & $(0.52-1.24)$ \\
\hline Current combined use ${ }^{\mathrm{b}}$ & 54 & 1.45 & 1.16 & $(0.78-1.70)$ & 1.05 & $(0.70-1.57)$ \\
\hline Current other NIAD use & 15 & 0.99 & 0.85 & $(0.48-1.53)$ & 0.76 & $(0.41-1.39)$ \\
\hline Current SGLT2 - I use & 16 & 0.97 & 0.86 & $(0.48-1.53)$ & 0.70 & $(0.38-1.29)$ \\
\hline \multicolumn{7}{|c|}{$\begin{array}{l}\text { By concomitant antihypertensive use in the previous } \\
3 \text { months }\end{array}$} \\
\hline \multicolumn{7}{|l|}{ Loop diuretics } \\
\hline Yes & $<5$ & 1.36 & 1.24 & $(0.17-8.99)$ & 0.31 & $(0.04-2.34)$ \\
\hline No & 15 & 0.95 & 0.84 & $(0.46-1.52)$ & 0.76 & $(0.41-1.42)$ \\
\hline \multicolumn{7}{|l|}{ Thiazide diuretics } \\
\hline Yes & $<5$ & 0.94 & 0.83 & $(0.20-3.41)$ & 0.64 & $(0.15-2.70)$ \\
\hline No & 14 & 0.98 & 0.86 & $(0.47-1.58)$ & 0.71 & $(0.38-1.34)$ \\
\hline \multicolumn{7}{|c|}{ Potassium sparing diuretics } \\
\hline Yes & $<5$ & 2.98 & 2.51 & $(0.35-18.21)$ & 0.62 & $(0.08-4.72)$ \\
\hline No & 15 & 0.93 & 0.82 & $(0.45-1.48)$ & 0.71 & $(0.38-1.31)$ \\
\hline \multicolumn{7}{|l|}{ Beta-blockers } \\
\hline Yes & 5 & 1.69 & 1.39 & $(0.55-3.52)$ & 0.93 & $(0.36-2.41)$ \\
\hline No & 11 & 0.81 & 0.73 & $(0.37-1.42)$ & 0.63 & $(0.32-1.27)$ \\
\hline \multicolumn{7}{|l|}{ ACE-inhibitors } \\
\hline Yes & 9 & 1.25 & 1.05 & $(0.51-2.15)$ & 0.73 & $(0.34-1.54)$ \\
\hline
\end{tabular}




\begin{tabular}{|c|c|c|c|c|c|c|}
\hline No & 7 & 0.75 & 0.69 & $(0.31-1.55)$ & 0.68 & $(0.30-1.54)$ \\
\hline \multicolumn{7}{|c|}{ Angiotensin II receptor blockers } \\
\hline Yes & $<5$ & 1.49 & 1.30 & $(0.47-3.62)$ & 1.27 & $(0.45-3.60)$ \\
\hline No & 12 & 0.87 & 0.77 & $(0.40-1.46)$ & 0.61 & $(0.31-1.19)$ \\
\hline \multicolumn{7}{|c|}{ By signs of hypovolemia in the previous 12 months $^{c}$} \\
\hline \multicolumn{7}{|c|}{ Serum urea/creatinine ratio $>0.1$} \\
\hline Yes & $<5$ & 0.69 & 0.72 & $(0.10-5.24)$ & 0.49 & $(0.07-3.61)$ \\
\hline No & 15 & 1.00 & 0.87 & $(0.48-1.57)$ & 0.73 & $(0.39-1.35)$ \\
\hline
\end{tabular}

Abbreviations: LLA: lower limb amputation; IR: incidence rate; PY: person years; HR: hazard ratio; CI: confidence interval; NIAD: non-insulin anti-diabetic drug; SU: sulphonylurea; DPP4-I: dipeptidyl peptidase-4 inhibitor; SGLT2-I: sodium-glucose cotransporter-2 inhibitor; ACE: angiotensin converting enzyme.

${ }^{a}$ Adjusted for sex, age, smoking status, diabetes duration, the use of insulin in the 6 months before, a history of retinopathy, neuropathy, foot infection, peripheral vascular disease, skin ulcer and previous diabetic foot ulcer or LLA.

${ }^{b}$ Combined use of at least two of the following NIADs: an SU and/or DPP4-I and/or SGLT2-I.

${ }^{c}$ There were no SGLT2-I users with a record of dehydration/hypovolemia or oliguria/anuria.

The number of included confounders in each Cox regression model that estimated adjusted HRs was based on a maximum of one confounder per ten events [30].

we reduced the gap allowed in the continuous duration of use from 60 to 30 days. The HRs for $<1.0$ year, 1.0-1.9 years and $\geq 2.0$ years of continuous duration of use were $0.62(95 \%$ CI $0.29-1.34), 0.64$ (95\% CI $0.20-2.11)$ and 1.27 (95\% CI $0.44-$ 3.66), respectively. Excluding individuals with previous LLAs in our third sensitivity analysis did not lead to different findings. There were 11 LLAs left in the current SGLT2I group and the fully adjusted HR for LLA in current SGLT2-I use compared to current SU use was 0.58 (95\% CI $0.28-1.23)$.

\section{DISCUSSION}

The present study shows that there was no increased risk of LLA with current SGLT2-I use compared to current SU use in a population of T2DM patients treated in primary care, with a relatively low number of micro- or macrovascular complications. Additionally, we did not find a higher risk of LLA with increasing cumulative dose exposure or longer continuous duration of SGLT2-I use. Concomitant use of SGLT2-Is with diuretics and renin-angiotensin system blockers was not associated with an increased risk of LLA and neither was the presence of signs of hypovolemia. Furthermore, we found no association between the use of SGLT2-I and different levels of LLA as well as with diabetic foot ulcer.

The results of this study are in line with the findings of a meta-analysis of RCTs in which no increased risk of LLA was observed with SGLT2-I use compared to standard treatment or placebo (OR 1.30 [95\%CI 0.93-1.83]) [6]. The CANVAS Program was included as one of the RCTs in this meta-analysis. The results of this particular trial are not in line with the current findings, as an almost two-fold increase in the risk of LLA was associated with canagliflozin use compared to placebo (HR 1.97 [95\%CI 1.41-2.75]) during a median follow-up time of 2.4 years [7]. These contrasting findings could be due to several differences in the study population and study design. The CANVAS Program included a population with a markedly higher cardiovascular risk profile than the current study population. In addition, there were fewer women, the participants were older, had longer T2DM duration, more neuropathy and more previous LLAs; all factors associated with an increased risk of LLA [20-23].
Besides, the use of an intention to treat analysis might have caused overestimation of canagliflozin exposure and the use of a placebo group as a reference instead of an active comparator might have augmented differences between the groups. Ultimately, the results of the CANVAS Program were nullified by the other studies included in the previously mentioned meta-analysis of RCTs, and the overall result of this meta-analysis was in line with our findings [6]. Moreover, our results are in line with a meta-analysis of observational studies [13] and another observational cohort study [24] in which no increased risk of LLA associated with SGLT2-I use was found. In several other cohort studies, an increased risk of LLA was observed with SGLT2-I use [810, 25]. However, these studies may have suffered from time-lag bias as other lines of treatment, including metformin users, were used as reference groups [26]. Finally, as suggested in a previous commentary [14] and a metaanalysis of RCTs [27], only canagliflozin might be associated with an increased risk of LLA; in pooled analyses of RCTs of dapagliflozin [28] and empagliflozin [29], no such increased risk was observed. In line with these findings, we observed a numerical higher incidence rate of LLAs with canagliflozin compared to the other SGLT2-Is in the current study. However, the numbers were too small to perform a statistical analysis.

In the current study, we explored whether hypovolemia due to the SGLT2-I-induced increase in renal glucose excretion, followed by a decrease in peripheral tissue perfusion [15], was associated with an increased risk of LLA. This potential mechanism was supported by the previous observation that volume depletion and osmotic diuresis were more common in the canagliflozin group compared to the placebo group in the CANVAS Program [7]. Besides, diuretic use has previously been associated with an increased risk of LLA in individuals with T2DM [16]. The proposed mechanism of hypovolemia suggests that long-term high dose users of SGLT2-Is would have a higher risk of LLA than shortterm low dose users. However, we did not observe a doseresponse relationship nor an increase in the risk of LLA over a longer period of continuous use. Besides, we did not find an increased risk of LLA in current SGLT2-I use with the presence of signs of hypovolemia or with concomitant diuretic use in the current study. 
The current study has several strengths. The duration of follow-up in the study is longest among previous cohort studies and approaches the duration of the CANVAS Program [7], suggesting that we captured the time frame in which LLAs might occur. During this follow-up time, approximately a quarter of all SGLT2-I users had more than two years of continuous duration of use and we were able to track their cumulative dose exposure. We used a primary care database that is more representative of the general population as compared to RCTs in which only patients with very specific inclusion criteria are selected. Besides, the use of 30-day intervals for drug exposure reduced the risk of misclassification of exposure. Finally, we minimized the risk of time lag bias by using a well-defined reference group in the same line of therapy as SGLT2-Is according to British guidelines [30] and with similar metabolic control, and by correcting the analyses for T2DM duration and insulin use.

Our study also has several limitations. Despite the substantial size of the study population, the number of LLAs was limited. Due to this small number of events, the stratification of current SGLT2-I users by the different SGLT2-Is to determine a substance effect did not yield a sufficient number of events. Also, we were limited in the number of confounders we could correct for. As a rule of thumb, we included one confounder per 10 events [31]. In case the number of confounders with $>5 \%$ change in the betacoefficient exceeded this rule of thumb, we eliminated the confounders with the lowest impact. Although we used a reference group with similar disease severity and corrected for available confounders, such as T2DM duration and insulin use, SGLT2-I users appear to be a specific group of patients, and channeling bias may have occurred to some extent [32]. Moreover, as in all observational studies, residual confounding must be considered when interpreting the results. Limited data was available on the characteristics of which we assumed could be signs of hypovolemia. Besides, underestimation of comorbidities might have led to insufficient correction for risk for LLA, which could have caused a slight distortion of the actual effect of SGLT2-I use. We suspect underestimation of the number of LLAs as the observed IR in our study population is lower than previously reported numbers in the United Kingdom [33] and in American populations [1, 34]. The degree of underestimation of both comorbidities and LLAs is likely to be equal in all groups and therefore may have masked a true association.

\section{CONCLUSION}

The results of the current study suggest that SGLT2-I use is not associated with an increased risk of LLA compared to SU use in a general diabetic population. This was supported by the findings that the risk did not increase with increasing cumulative dose exposure or longer continuous duration of use. However, the number of events was limited and a canagliflozin-specific effect cannot be ruled out given the relatively low number of patients using this drug in the study population. Nevertheless, our data suggest that the use of dapagliflozin or empagliflozin is not a major risk factor for LLA. Concomitant use of diuretics and renin-angiotensin system blockers, as well as the presence of signs of hypovolemia were not associated with an increased risk of
LLA. Future studies powered to detect potential differences between individual SGLT2-Is and with a more extensive recording of (signs of) hypovolemia would be a useful addition.

\section{ETHICAL APPROVAL AND CONSENT TO PARTIC- IPATE}

Not applicable.

\section{HUMAN AND ANIMAL RIGHTS}

Not applicable.

\section{CONSENT FOR PUBLICATION}

Not applicable.

\section{AVAILABILITY OF DATA AND MATERIALS}

Not applicable.

\section{FUNDING}

Not applicable.

\section{CONFLICT OF INTEREST}

JvB reports grants and personal fees from Amgen, grants and personal fees from Eli Lilly, personal fees from UCB, outside the submitted work.

FV supervises 3 Ph.D. students who are employed with F. Hoffmann La Roche Ltd., (Basel, Switzerland / Welwyn Garden City, UK). He has not received any fees or reimbursements for this, and the topics of their Ph.D. are not related to the current study.

PV is head of research in the Steno Diabetes Center North Denmark funded by the Novo Nordisk Foundation.

\section{ACKNOWLEDGEMENTS}

Not applicable.

\section{REFERENCES}

[1] Gregg EW, Li Y, Wang J, et al. Changes in diabetes-related complications in the United States, 1990-2010. N Engl J Med 2014; 370(16): 1514-23. http://dx.doi.org/10.1056/NEJMoa1310799 PMID: 24738668

[2] Costa RHR, Cardoso NA, Procópio RJ, Navarro TP, Dardik A, de Loiola Cisneros L. Diabetic foot ulcer carries high amputation and mortality rates, particularly in the presence of advanced age, peripheral artery disease and anemia. Diabetes Metab Syndr 2017; 11(Suppl. 2): S583-7. http://dx.doi.org/10.1016/j.dsx.2017.04.008 PMID: 28465149

[3] Tahrani AA, Barnett AH, Bailey CJ. SGLT inhibitors in management of diabetes. Lancet Diabetes Endocrinol 2013; 1(2): 140-51. http://dx.doi.org/10.1016/S2213-8587(13)70050-0 PMID: 24622320

[4] Li J, Gong Y, Li C, Lu Y, Liu Y, Shao Y. Long-term efficacy and safety of sodium-glucose cotransporter-2 inhibitors as add-on to 
metformin treatment in the management of type 2 diabetes mellitus: A meta-analysis. Medicine (Baltimore) 2017; 96(27)e7201 http://dx.doi.org/10.1097/MD.0000000000007201 PMID: 28682870

[5] Mearns ES, Sobieraj DM, White CM, et al. Comparative efficacy and safety of antidiabetic drug regimens added to metformin monotherapy in patients with type 2 diabetes: a network meta-analysis. PLoS One 2015; 10(4)e0125879

http://dx.doi.org/10.1371/journal.pone.0125879 PMID: 25919293

[6] Dorsey-Treviño EG, González-González JG, Alvarez-Villalobos N, et al. Sodium-glucose cotransporter 2 (SGLT-2) inhibitors and microvascular outcomes in patients with type 2 diabetes: systematic review and meta-analysis. J Endocrinol Invest 2020; 43(3): 289304.

http://dx.doi.org/10.1007/s40618-019-01103-9 PMID: 31489568

[7] Neal B, Perkovic V, Mahaffey KW, et al. CANVAS Program Collaborative Group. Canagliflozin and Cardiovascular and Renal Events in Type 2 Diabetes. N Engl J Med 2017; 377(7): 644-57. http://dx.doi.org/10.1056/NEJMoa1611925 PMID: 28605608

[8] Udell JA, Yuan Z, Rush T, Sicignano NM, Galitz M, Rosenthal N. Cardiovascular Outcomes and Risks After Initiation of a Sodium Glucose Cotransporter 2 Inhibitor: Results From the EASEL Population-Based Cohort Study (Evidence for Cardiovascular Outcomes With Sodium Glucose Cotransporter 2 Inhibitors in the Real World). Circulation 2018; 137(14): 1450-9.

http://dx.doi.org/10.1161/CIRCULATIONAHA.117.031227 PMID: 29133607

[9] Chang HY, Singh S, Mansour O, Baksh S, Alexander GC. Association Between Sodium-Glucose Cotransporter 2 Inhibitors and Lower Extremity Amputation Among Patients With Type 2 Diabetes. JAMA Intern Med 2018; 178(9): 1190-8.

http://dx.doi.org/10.1001/jamainternmed.2018.3034 PMID: 30105373

[10] Yang JY, Wang T, Pate V, et al. Sodium-glucose co-transporter-2 inhibitor use and risk of lower-extremity amputation: Evolving questions, evolving answers. Diabetes Obes Metab 2019; 21(5): 1223-36.

http://dx.doi.org/10.1111/dom.13647 PMID: 30697897

[11] Adimadhyam S, Lee TA, Calip GS, Smith Marsh DE, Layden BT, Schumock GT. Risk of amputations associated with SGLT2 inhibitors compared to DPP-4 inhibitors: A propensity-matched cohort study. Diabetes Obes Metab 2018; 20(12): 2792-9.

http://dx.doi.org/10.1111/dom.13459 PMID: 29971914

[12] Yuan Z, DeFalco FJ, Ryan PB, et al. Risk of lower extremity amputations in people with type 2 diabetes mellitus treated with sodium-glucose co-transporter-2 inhibitors in the USA: A retrospective cohort study. Diabetes Obes Metab 2018; 20(3): 582-9. http://dx.doi.org/10.1111/dom.13115 PMID: 28898514

[13] Ryan PB, Buse JB, Schuemie MJ, et al. Comparative effectiveness of canagliflozin, SGLT2 inhibitors and non-SGLT2 inhibitors on the risk of hospitalization for heart failure and amputation in patients with type 2 diabetes mellitus: A real-world meta-analysis of 4 observational databases (OBSERVE-4D). Diabetes Obes Metab 2018; 20(11): 2585-97.

http://dx.doi.org/10.1111/dom.13424 PMID: 29938883

[14] Monteiro-Soares M, Ribeiro-Vaz I, Boyko EJ. Canagliflozin should be prescribed with caution to individuals with type 2 diabetes and high risk of amputation. Diabetologia 2019; 62(6): 900-4. http://dx.doi.org/10.1007/s00125-019-4861-x PMID: 30941448

[15] Fadini GP, Avogaro A. SGLT2 inhibitors and amputations in the US FDA Adverse Event Reporting System. Lancet Diabetes Endocrinol 2017; 5(9): 680-1.

http://dx.doi.org/10.1016/S2213-8587(17)30257-7 PMID: 28733172

[16] Potier L, Roussel R, Velho G, et al. Lower limb events in individuals with type 2 diabetes: evidence for an increased risk associated with diuretic use. Diabetologia 2019; 62(6): 939-47. http://dx.doi.org/10.1007/s00125-019-4835-z PMID: 30809716

[17] Herrett E, Gallagher AM, Bhaskaran K, et al. Data Resource Profile: Clinical Practice Research Datalink (CPRD). Int J Epidemiol 2015; 44(3): 827-36. http://dx.doi.org/10.1093/ije/dyv098 PMID: 26050254

CPRD. Application guidance notes

2020 .

https://cprd.com/sites/default/files/Completion\%20of\%20the $\% 20$

ISAC\%20Protocol\%20Application\%20Form\%20February\%20202

$0 . p d f$

[19] WHO Collaborating Centre for Drug Statistics Methodology. https://www.whocc.no/atc_ddd_index/

[20] Boyko EJ, Seelig AD, Ahroni JH. Limb- and Person-Level Risk Factors for Lower-Limb Amputation in the Prospective Seattle Diabetic Foot Study. Diabetes Care 2018; 41(4): 891-8. http://dx.doi.org/10.2337/dc17-2210 PMID: 29439130

[21] Gurney JK, Stanley J, York S, Rosenbaum D, Sarfati D. Risk of lower limb amputation in a national prevalent cohort of patients with diabetes. Diabetologia 2018; 61(3): 626-35. http://dx.doi.org/10.1007/s00125-017-4488-8 PMID: 29101423

[22] Jiang Y, Ran X, Jia L, et al. Epidemiology of type 2 diabetic foot problems and predictive factors for amputation in China. Int $\mathrm{J}$ Low Extrem Wounds 2015; 14(1): 19-27. http://dx.doi.org/10.1177/1534734614564867 PMID: 25573978

[23] Monteiro-Soares M, Martins-Mendes D, Vaz-Carneiro A, DinisRibeiro M. Lower-limb amputation following foot ulcers in patients with diabetes: classification systems, external validation and comparative analysis. Diabetes Metab Res Rev 2015; 31(5): 51529.

http://dx.doi.org/10.1002/dmrr.2634 PMID: 25529456

[24] Dawwas GK, Smith SM, Park H. Cardiovascular outcomes of sodium glucose cotransporter-2 inhibitors in patients with type 2 diabetes. Diabetes Obes Metab 2019; 21(1): 28-36. http://dx.doi.org/10.1111/dom.13477 PMID: 30039524

[25] Ueda P, Svanström H, Melbye M, et al. Sodium glucose cotransporter 2 inhibitors and risk of serious adverse events: nationwide register based cohort study. BMJ 2018; 363: k4365.

http://dx.doi.org/10.1136/bmj.k4365 PMID: 30429124

[26] Suissa S. Lower Risk of Death With SGLT2 Inhibitors in Observational Studies: Real or Bias? Diabetes Care 2018; 41(1): 6-10. http://dx.doi.org/10.2337/dc17-1223 PMID: 29263192

[27] Li D, Yang JY, Wang T, Shen S, Tang H. Risks of diabetic foot syndrome and amputation associated with sodium glucose cotransporter 2 inhibitors: A Meta-analysis of Randomized Controlled Trials. Diabetes Metab 2018; 44(5): 410-4. http://dx.doi.org/10.1016/j.diabet.2018.02.001 PMID: 29506779

[28] Jabbour S, Seufert J, Scheen A, Bailey CJ, Karup C, Langkilde AM. Dapagliflozin in patients with type 2 diabetes mellitus: A pooled analysis of safety data from phase IIb/III clinical trials. Diabetes Obes Metab 2018; 20(3): 620-8.

http://dx.doi.org/10.1111/dom.13124 PMID: 28950419

[29] Kohler S, Zeller C, Iliev H, Kaspers S. Safety and Tolerability of Empagliflozin in Patients with Type 2 Diabetes: Pooled Analysis of Phase I-III Clinical Trials. Adv Ther 2017; 34(7): 1707-26. http://dx.doi.org/10.1007/s12325-017-0573-0 PMID: 28631216

[30] National Institute for Health and Care Excellence. https://www.nice.org.uk/guidance/ng28

[31] Peduzzi P, Concato J, Feinstein AR, Holford TR. Importance of events per independent variable in proportional hazards regression analysis. II. Accuracy and precision of regression estimates. J Clin Epidemiol 1995; 48(12): 1503-10

http://dx.doi.org/10.1016/0895-4356(95)00048-8 PMID: 8543964

[32] Petri H, Urquhart J. Channeling bias in the interpretation of drug effects. Stat Med 1991; 10(4): 577-81.

http://dx.doi.org/10.1002/sim.4780100409 PMID: 2057656

[33] Holman N, Young RJ, Jeffcoate WJ. Variation in the recorded incidence of amputation of the lower limb in England. Diabetologia 2012; 55(7): 1919-25.

http://dx.doi.org/10.1007/s00125-012-2468-6 PMID: 22398645

[34] Geiss LS, Li Y, Hora I, Albright A, Rolka D, Gregg EW. Resurgence of Diabetes-Related Nontraumatic Lower-Extremity Amputation in the Young and Middle-Aged Adult U.S. Population. Diabetes Care 2019; 42(1): 50-4. http://dx.doi.org/10.2337/dc18-1380 PMID: 30409811 